\title{
PREDICTION OF FRACTURE HEALING IN THE TIBIA BY QUANTITATIVE RADIONUCLIDE IMAGING
}

\author{
M. A. SMITh, E. A. JONES, R. K. STRAChaN, J. J. NICOLL, J. J. K. BEST, P. TOTHILL, S. P. F. HUGHES \\ From the Royal Infirmary, Edinburgh
}

\begin{abstract}
The uptake of ${ }^{99} \mathrm{~m}$ Tc-MDP was studied in 73 patients after a tibial fracture. The image obtained five minutes after injection during a period between one and four weeks after fracture was found to be related to the incidence of non-union after six months. A ratio of 1.3 between the uptake at the fracture site and at normal bone adjacent to it predicted non-union in an individual patient with a sensitivity of about $70 \%$ and a specificity of $90 \%$.
\end{abstract}

It has been recognised for many years that there is an increased uptake of bone scanning agents at the site of a fracture and there have been several reports on bone scans as indicators of fracture healing. Various radionuclides such as ${ }^{32} \mathrm{P}$ (Tucker 1950), ${ }^{85} \mathrm{Sr}$ (Bauer and

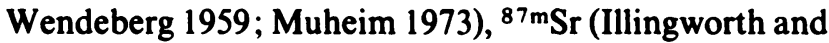
Schiess 1971; Johanssen 1973) and ${ }^{18} \mathrm{~F}$ (Riggens et al. 1974) have been used to investigate fracture healing without a great deal of success. Technetium $99 \mathrm{~m}$ phosphate compounds such as ${ }^{99 m} \mathrm{Tc}-\mathrm{Sn}$-pyrophosphate (Lund et al. 1978) have also been investigated but it is the compound $99 \mathrm{~m}$ Tc-methylene diphosphonate (MDP) which seems the most promising in the investigation of fracture healing (Hughes 1980).

Most of the research using MDP has concentrated on the qualitative assessment of scans recorded at two to four hours after injection. Matin (1979) and Desai et al. (1980), however, showed that there was increased uptake at fractures sites. Auchincloss and Watt (1982), in a study of fractures of the lower leg, demonstrated a significant rela finship between uptake at the fracture site and time to union; they suggested that the two-hour scan may be of value in the prediction of delayed healing, though there was a considerable degree of overlap between the groups

M. A. Smith, MSc, PhD, Senior Lecturer

Department of Radiological Sciences, United Medical and Dental School, Guy's Hospital, St Thomas Street, London SE1 9RT, England.

E. A. Jones, MSc, Senior Physicist

R. K. Strachan, FRCS, Lecturer

J. J. Nicoll, PhD, Senior Physicist

J. J. K. Best, FRCP, FRCR, Professor of Medical Radiology

P. Tothill, PhD, FInstP, FRSE, Reader in Medical Physics

S. P. F. Hughes, MS, FRCS Ed, FRCS, FRCSI, Professor of Orthopaedic Surgery

Departments of Medical Physics and Medical Engineering, Orthopaedic Surgery and Medical Radiology, The Royal Infirmary, Edinburgh EH3 9YW, Scotland.

Requests for reprints should be sent to Mr M. A. Smith.

(C) 1987 British Editorial Society of Bone and Joint Surgery 0301-620X/87/3099\$2.00 in their study. However, Jacobs et al. (1981) and Gregg, Barsoum and Clayton (1983) came to the opposite conclusion. The only previous report on MDP uptake very soon after injection was a small study (Jacobs et al. 1981) which demonstrated a relationship between the rate of uptake and time to union.

It has been shown that the MDP uptake at two to four hours after injection is a function of both regional blood flow and bone formation (Lavender et al. 1979). Given the relatively slow transfer of MDP from blood through the bone fluids to bone itself with a peak at about one hour (Hughes et al. 1978; Makler and Charkes 1980), the uptake of MDP soon after injection should be largely dependent on blood flow alone. If the interruption of blood flow in the bone is the reason for the number of tibial fractures which fail to unite, then MDP uptake, particularly soon after injection, could be a valuable predictor of non-union. If bone blood flow is the predominant factor, then it is important that studies be made when the reactive increase in blood flow is maximal.

Previous studies using MDP to investigate fracture healing (Jacobs et al. 1981; Auchincloss and Watt 1982) have demonstrated that various indices are related to the time to union. Our aim was to conduct a prospective study to investigate the differences in early uptake of MDP between patients obtaining union in normal time and those developing non-union. We hoped to develop a technique which could predict non-union soon after fracture in order to allow consideration of an early prophylactic operation.

\section{PATIENTS AND METHODS}

All patients aged from 16 to 55 years with a fractured tibia and a normal contralateral limb admitted to the Royal Infirmary, Edinburgh from January 1982 to July 
Table I. Details of the 73 tibial fractures included in the study

\begin{tabular}{lc}
\hline & Number \\
\hline Fracture of tibia and fibula & 62 \\
Fracture of tibia only & 11 \\
Type of fracture & \\
Transverse & 24 \\
Oblique & 35 \\
Spiral & 14 \\
Fixation & \\
Internal & 4 \\
External & 13 \\
Plaster & 56 \\
Compound injury (Gustilo and Anderson 1976) & \\
Grade 0 & 40 \\
Grade 1 & 15 \\
Grade 2 & 10 \\
Grade 3 & 8 \\
Comminution (Johner and Wruhs 1983) & \\
Type A & 23 \\
Type B & 32 \\
Type C & 18 \\
Clinical grading (Ellis 1958) & \\
Group I & \\
Group II & 13 \\
Group III & 48 \\
\hline
\end{tabular}

1984 were considered for this study. Exclusions were those with severe multiple injuries and those who declined to take part. In all, 86 patients were accepted into the series, but 13 were subsequently withdrawn because of clinical problems or failure to attend. We accepted all types of tibial fracture (Table I) and all methods of management. There were 27 patients aged 15 to 19 years, 36 aged 20 to 29 years, 12 aged 30 to 39 years and 11 aged from 40 to 55 years.

In addition to the routine of management, each patient was examined by the same orthopaedic surgeon at monthly intervals in order to assess the state of healing of the fracture. He had no access to the results of the bone scan but, using a combination of radiographic and clinical criteria, recorded each patient as showing union, delayed union or non-union. Normal union was recorded for the fractures which had united within four months, and delayed union where fractures had united between four and six months. Non-union was recorded for those fractures which had not united by six months.

Our aim was to perform quantitative bone scans at two, six and 12 weeks after the injury. These times were chosen for a number of reasons. After a fracture there is an immediate decrease in blood supply to that bone; this is followed by an increase which reaches a maximum after 10 to 14 days in the canine tibia (Paradis and Kelly 1975; McCarthy and Hughes 1984). This increased blood flow is associated with new bone formation as the fracture heals. Two weeks after injury is a suitable time with respect to the mobility of the patient, and is also the time when the increased blood flow should reach a plateau. Operation for failure to unite is commonly considered after about 12 weeks; Jacobs et al. (1981) were able to show a difference in uptake between cases of delayed and of non-union at this time. We therefore performed a scan at 12 weeks and also at an intermediate time to assess the healing process. The work of Lund et al. (1978) suggested that six weeks was an appropriate time.

At each visit, each patient was given an intravenous

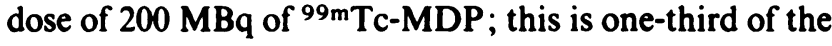
dose normally given for a routine bone scan. Before the injection the radioactivity of the syringe was measured by scintillation counter against a ${ }^{99 \mathrm{~m}} \mathrm{Tc}-\mathrm{MDP}$ standard which was approximately $1 \%$ of the injected activity. The patient was positioned supine on a scanning bed below which a gamma camera had both lower legs in its field of view. A Technicare 110 gamma camera with a high sensitivity collimator and an MCS-560 computer processor were used. The ${ }^{99 \mathrm{~m}} \mathrm{Tc}-\mathrm{MDP}$ was administered as a bolus injection in the right antecubital fossa and was flushed through with $20 \mathrm{ml}$ of saline. A dynamic series of $30 \times 10$ second images were obtained from the time of injection for 300 seconds. After this a static image was collected from 300 to 800 seconds post-injection. This static image was termed the "early uptake". After about two hours the patient returned to the scanning room and was positioned as before. A 300 second static scan was then collected which was termed the "late uptake". This late uptake scan was obtained with the same gamma camera but with a medium resolution, lower sensitivity collimator. After each early and late uptake scan the $99 \mathrm{~m} \mathrm{Tc}-\mathrm{MDP}$ standard was placed in the centre of the collimator field and measured for 100 seconds so that the absolute uptake at the fracture site could be determined.

The results from the bone scans were analysed using the computer to measure the radioactivity within regions of interest (Fig. 1). These were defined as: $A$, round the
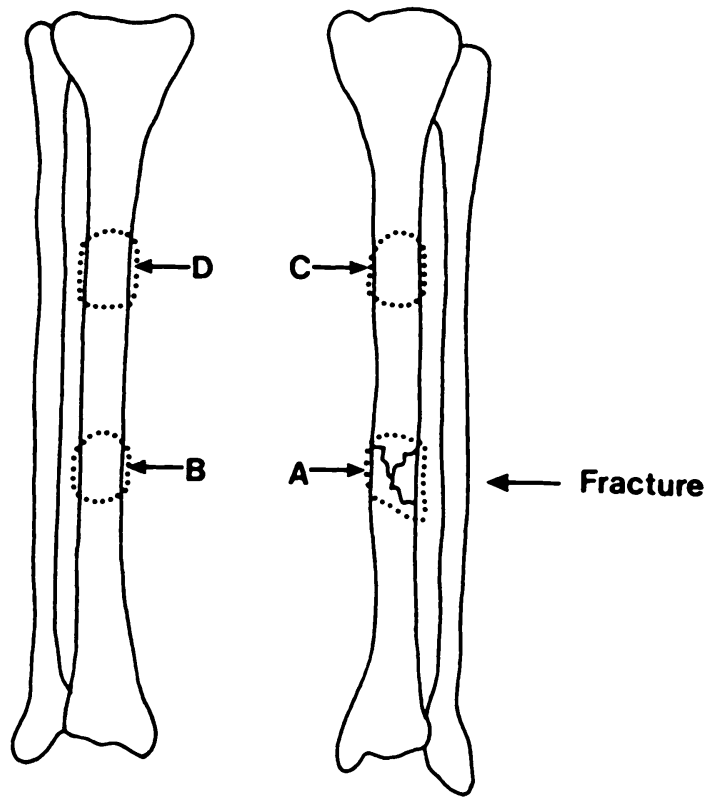

Fig. 1

Diagram to show the regions of interest A, B, C and D in relation to the site of the fracture. 
Table II. The ratios between activity levels on "early uptake" and "late uptake" scans at the three visits for each of the groups (mean \pm s.d.)

\begin{tabular}{|c|c|c|c|c|c|c|c|c|c|c|c|c|c|c|c|}
\hline & \multicolumn{12}{|l|}{ Ratios } & & & \\
\hline & \multicolumn{3}{|l|}{$\mathbf{A} / \mathbf{B}$} & \multicolumn{3}{|l|}{$\mathbf{A} / \mathbf{C}$} & \multicolumn{3}{|l|}{ C/D } & \multicolumn{3}{|c|}{$A / B \div C / D$} & \multicolumn{3}{|c|}{ Number of patients } \\
\hline & $\mathbf{U}$ & D & NU & $\mathbf{U}$ & D & $\mathbf{N U}$ & $\mathbf{U}$ & D & NU & $\mathbf{U}$ & D & $\mathbf{N U}$ & $\mathbf{U}$ & D & $\mathbf{N U}$ \\
\hline $\begin{array}{c}\text { First visit } \\
\text { Early } \\
\text { Late }\end{array}$ & $\begin{array}{r}2.78 \\
\pm 1.18 \\
4.97 \\
\pm 1.76\end{array}$ & $\begin{array}{r}1.95 \\
\pm 0.67 \\
4.31 \\
\pm 1.60\end{array}$ & $\begin{array}{r}2.38 \\
\pm 0.74 \\
4.56 \\
\pm 1.33\end{array}$ & $\begin{array}{r}1.69 \\
\pm 0.39 \\
2.51 \\
\pm 0.99\end{array}$ & $\begin{array}{r}1.22 \\
\pm 0.12 \\
1.86 \\
\pm 0.61\end{array}$ & $\begin{array}{r}1.26 \\
\pm 0.36 \\
1.62 \\
\pm 0.57\end{array}$ & $\begin{array}{r}1.36 \\
\pm 0.44 \\
2.30 \\
\pm 0.71\end{array}$ & $\begin{array}{r}1.27 \\
\pm 0.37 \\
2.35 \\
\pm 0.98\end{array}$ & $\begin{array}{r}1.53 \\
\pm 0.48 \\
2.88 \\
\pm 0.94\end{array}$ & $\begin{array}{r}2.16 \\
\pm 0.96 \\
2.47 \\
+1.49\end{array}$ & $\begin{array}{r}1.55 \\
\pm 0.38 \\
1.91 \\
\pm 0.66\end{array}$ & $\begin{array}{r}1.70 \\
\pm 0.77 \\
1.72 \\
\pm 0.75\end{array}$ & 32 & 9 & 10 \\
\hline $\begin{array}{c}\text { Second visit } \\
\text { Early } \\
\text { Late }\end{array}$ & $\begin{array}{r}2.38 \\
\pm 0.73 \\
6.78 \\
\pm 2.52\end{array}$ & $\begin{array}{r}2.16 \\
\pm 0.61 \\
6.34 \\
\pm 2.55\end{array}$ & $\begin{array}{r}2.03 \\
\pm 0.57 \\
5.45 \\
\pm 1.51\end{array}$ & $\begin{array}{r}1.84 \\
\pm 0.55 \\
3.23 \\
\pm 1.25\end{array}$ & $\begin{array}{r}1.65 \\
\pm 0.39 \\
2.82 \\
\pm 0.80\end{array}$ & $\begin{array}{r}1.79 \\
\pm 0.69 \\
2.41 \\
\pm 0.80\end{array}$ & $\begin{array}{r}1.12 \\
\pm 0.38 \\
2.09 \\
\pm 0.56\end{array}$ & $\begin{array}{r}1.14 \\
\pm 0.30 \\
2.40 \\
\pm 0.64\end{array}$ & $\begin{array}{r}1.05 \\
\pm 0.32 \\
2.35 \\
\pm 0.74\end{array}$ & $\begin{array}{r}2.20 \\
\pm 0.60 \\
3.29 \\
\pm 1.17\end{array}$ & $\begin{array}{r}1.99 \\
\pm 0.66 \\
2.69 \\
\pm 0.96\end{array}$ & $\begin{array}{r}2.06 \\
\pm 0.80 \\
2.49 \\
\pm 0.95\end{array}$ & 34 & 8 & 12 \\
\hline $\begin{array}{c}\text { Third visit } \\
\text { Early } \\
\text { Late }\end{array}$ & $\begin{array}{r}2.62 \\
\pm 1.29 \\
7.54 \\
\pm 2.61\end{array}$ & $\begin{array}{r}2.79 \\
\pm 0.99 \\
9.13 \\
+2.89\end{array}$ & $\begin{array}{r}2.10 \\
\pm 0.63 \\
6.63 \\
\pm 2.67\end{array}$ & $\begin{array}{r}2.04 \\
\pm 0.57 \\
4.24 \\
\pm 1.79\end{array}$ & $\begin{array}{r}2.04 \\
\pm 0.56 \\
3.87 \\
\pm 1.68\end{array}$ & $\begin{array}{r}1.71 \\
\pm 0.36 \\
3.13 \\
\pm 1.09\end{array}$ & $\begin{array}{r}1.09 \\
\pm 0.37 \\
2.02 \\
\pm 0.62\end{array}$ & $\begin{array}{r}1.10 \\
\pm 0.28 \\
2.50 \\
\pm 1.25\end{array}$ & $\begin{array}{r}1.00 \\
\pm 0.23 \\
2.18 \\
\pm 0.97\end{array}$ & $\begin{array}{r}2.49 \\
\pm 0.92 \\
4.02 \\
+1.76\end{array}$ & $\begin{array}{r}2.67 \\
\pm 0.97 \\
3.84 \\
\pm 1.47\end{array}$ & $\begin{array}{r}2.14 \\
\pm 0.59 \\
3.39 \\
\pm 1.43\end{array}$ & 27 & 7 & 10 \\
\hline
\end{tabular}

$\mathrm{U}$, union

$D$, delayed union

NU, non-union

fracture site; $B$, over normal bone on the contralateral limb at the corresponding level; $C$, over normal bone above the fracture site; and $D$, over a corresponding region on the contralateral limb. When the fracture was too high in the tibia for enough normal bone to be available above it, region $\mathrm{C}$, and therefore region $\mathrm{D}$ also, were chosen in normal bone below the fracture site. The selection of these regions of interest was made by the same author (EAJ) on each occasion after study of a radiograph of the fractured bone. The late uptake scan was often used to assist in the retrospective choice of the regions for the early scan. The measurement of MDP uptake from the images and the assessment of fracture healing were both performed double-blind. The ratios of $\mathrm{A} / \mathrm{B}, \mathrm{A} / \mathrm{C}, \mathrm{C} / \mathrm{D}$ and $(\mathrm{A} / \mathrm{B}) \div(\mathrm{C} / \mathrm{D})$ were noted, after each result had been normalised for area. The latter two ratios were measured for comparison with the results of Auchincloss and Watt (1982). The attenuation of $141 \mathrm{keV}$ gamma photons through the plaster on a fractured leg was between $3 \%$ and $5 \%$, which is too small to distort the ratios significantly.

Since our results depended on the choice of the regions of interest, both intra-operator and interoperator variations were investigated. The scans of 20 patients were re-analysed six months after the initial analysis by the original observer (EAJ) and the variation between measured uptakes at the fracture site were noted. Inter-observer variation was assessed by an independent re-analysis of the most appropriate ratio by a second observer using all the scans (JJN). Differences in the sensitivity and specificity of the technique between the two observers were noted. The sensitivity of the prediction of non-union was defined as the proportion of patients developing non-union who could have been correctly identified. The specificity was defined as the proportion of patients obtaining normal union who could have been correctly predicted.

In addition, activity profiles along the length of the bone in the fractured leg were investigated. We also studied the automatic determination of the region of interest by the computer, and a range of computer programs was developed to define this region. After the operator had identified the approximate position of the region of high uptake at the fracture site, the program then included all pixels which showed more than a given percentage of the maximum uptake; cut-off levels of $70 \%, 80 \%$ and $90 \%$ were investigated.

\section{RESULTS}

Of the 73 patients admitted into the study, not all attended on all three occasions. Although it had been intended to obtain scans at two weeks, precise timing was not possible, so we analysed scans taken at the "first visit" from between one and four weeks after fracture. Two patients had evidence of infection at the time of scan and these results were excluded since infection is known to increase MDP uptake (Hughes et al. 1986). There were fewer exclusions from the results of scans taken between five and eight weeks after fracture, referred to as the "second visit", or between 10 and 15 weeks after injury, the "third visit".

The mean ratios obtained at each visit for the three groups of patients are listed in Table II. As would be expected, the ratios of most interest $(\mathrm{A} / \mathrm{B}$ and $\mathrm{A} / \mathrm{C})$ tend to decrease in the patients who eventually showed nonunion. For these ratios, the "non-union" group has a lower mean than the "union" group for both the early 
Table III. The $t$ value and significance of the difference between the groups with union and with non-union (Table II) for the ratios $A / C$ and A/B on early and late uptake

\begin{tabular}{clll}
\hline & Ratio & t value of difference & Significance \\
\hline $\begin{array}{c}\text { First risit } \\
\text { Early uptake }\end{array}$ & $\mathrm{A} / \mathrm{C}$ & 3.2 & \\
Late uptake & $\mathrm{A} / \mathrm{B}$ & 1.3 & $\mathrm{p}<0.005$ \\
& $\mathrm{~A} / \mathrm{C}$ & 3.5 & $\mathrm{NS}$ \\
& $\mathrm{A} / \mathrm{B}$ & 0.8 & $\mathrm{p}<0.005$ \\
Second risit & & & \\
Early uptake & $\mathrm{A} / \mathrm{C}$ & 0.2 & $\mathrm{NS}$ \\
Late uptake & $\mathrm{A} / \mathrm{B}$ & 1.7 & $\mathrm{NS}$ \\
& $\mathrm{A} / \mathrm{C}$ & 2.6 & $\mathrm{p}<0.05$ \\
& $\mathrm{~A} / \mathrm{B}$ & 2.2 & $\mathrm{p}<0.05$ \\
Third visit & & & \\
Early uptake & $\mathrm{A} / \mathrm{C}$ & 2.1 & $\mathrm{p}<0.05$ \\
& $\mathrm{~A} / \mathrm{B}$ & 1.6 & $\mathrm{NS}$ \\
Late uptake & $\mathrm{A} / \mathrm{C}$ & 2.3 & $\mathrm{p}<0.05$ \\
& $\mathrm{~A} / \mathrm{B}$ & 0.9 & $\mathrm{NS}$ \\
\hline
\end{tabular}

NS, not significant and late uptake at each visit. Table III records the significance of the difference between the union and the non-union groups for each of the three visits and for the different ratios. As expected from other reports, there is frequently a significant difference between the groups designated union and non-union.

However, the degree of overlap between the results from these groups is more important; an indication of this overlap can be obtained from comparison of the $t$ statistic for each group. The $t$ values indicate that the best separation between the union and non-union groups can be obtained from the $\mathrm{A} / \mathrm{C}$ ratio at the first visit. The only other significant differences between groups $(p<0.05)$ were obtained from the $A / B \div C / D$ ratio of the late uptake, recorded at the first visit and the second visit. Moreover, at the first visit the best separation of all was that obtained by using the $\mathrm{A} / \mathrm{C}$ ratio of the "early uptake" (Fig. 2). Although at the first visit the $t$ value for
Fig. 2

The results of the early uptake $\mathrm{A} / \mathrm{C}$ ratio at the first visit related to the time to union. The dashed line represents the ratio 1.3.

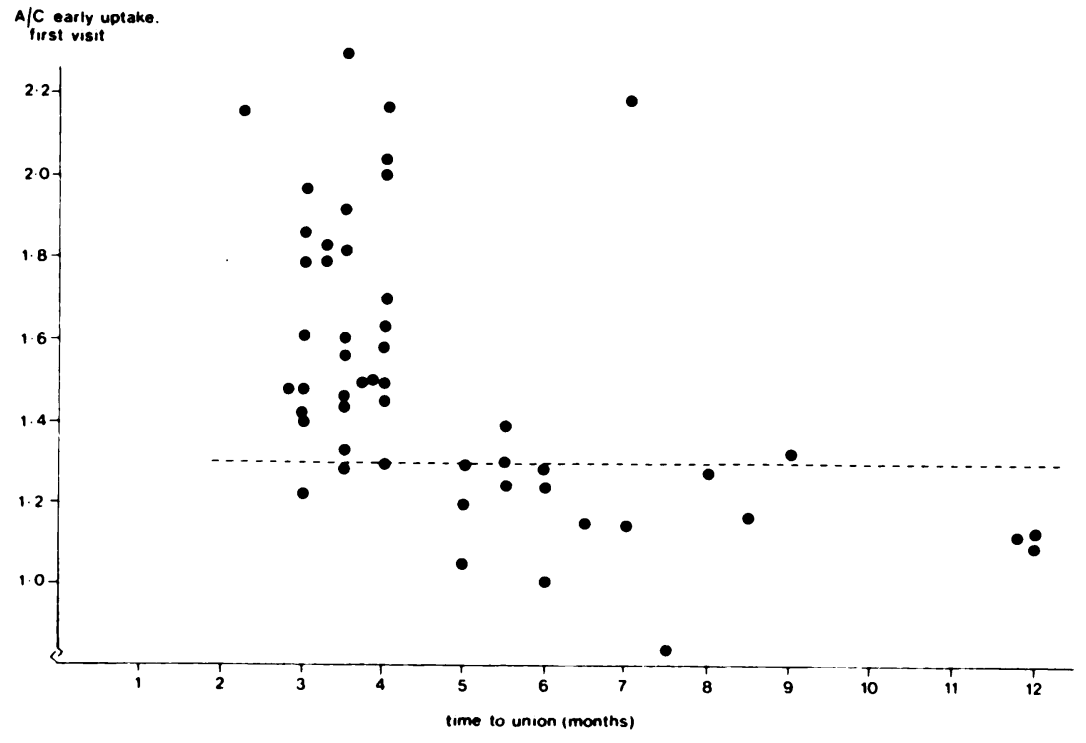

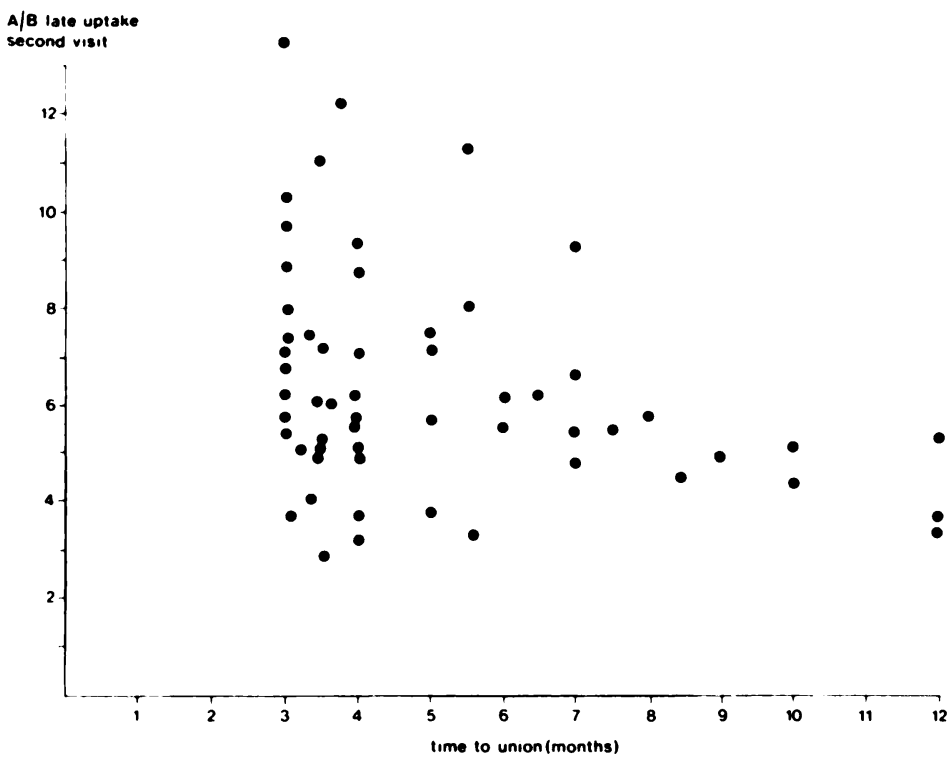

Fig. 3

Results for the late uptake A/B ratio at the second visit related to the time to union. 
Table IV. The sensitivity and specificity of early uptake $\mathrm{A} / \mathrm{C}$ ratio at the first visit in predicting non-union using three different ratios as cut-off values. A ratio greater than or equal to the cut-off value was taken to predict union. The complete set of results was independently analysed by two operators

\begin{tabular}{|c|c|c|c|c|c|}
\hline Operator & $\begin{array}{l}\text { Cut-of value } \\
\text { of } A / C \text { ratio }\end{array}$ & $\begin{array}{l}\text { Number of patients predicted } \\
\text { to unite within } 4 \text { months } \\
\text { (true total 19) }\end{array}$ & $\begin{array}{l}\text { Seasitivity } \\
\text { (per cent) }\end{array}$ & $\begin{array}{l}\text { Number of patients with predicted } \\
\text { delay or failure of union } \\
\text { (true total 32) }\end{array}$ & $\begin{array}{l}\text { Specificity } \\
\text { (per cent) }\end{array}$ \\
\hline$\underset{\text { JJN }}{\text { EAJ }}$ & 1.2 & $\begin{array}{r}10 \\
6\end{array}$ & $\begin{array}{l}53 \\
32\end{array}$ & $\begin{array}{l}32 \\
31\end{array}$ & $\begin{array}{r}100 \\
97\end{array}$ \\
\hline$\underset{\text { JJN }}{\text { EAJ }}$ & 1.3 & $\begin{array}{l}16 \\
12\end{array}$ & $\begin{array}{l}84 \\
63\end{array}$ & $\begin{array}{l}29 \\
28\end{array}$ & $\begin{array}{l}91 \\
88\end{array}$ \\
\hline $\begin{array}{l}\text { EAJ } \\
\text { JJN }\end{array}$ & 1.4 & $\begin{array}{l}18 \\
15\end{array}$ & $\begin{array}{l}95 \\
79\end{array}$ & $\begin{array}{l}28 \\
22\end{array}$ & $\begin{array}{l}88 \\
69\end{array}$ \\
\hline
\end{tabular}

the late uptake $\mathrm{A} / \mathrm{C}$ ratio was higher than the corresponding early uptake ratio, this was due to very high $\mathrm{A} / \mathrm{C}$ values in the union group at late uptake even though separation was not as good. The possibility of improving the separation by using both early and late $\mathrm{A} / \mathrm{C}$ ratios at the first visit was investigated. The product of these ratios gave no better separation between the groups than the early uptake $A / C$ ratio at the first visit on its own. The late uptake A/B ratio at the second visit is shown in Figure 3.

The absolute uptake in region $\mathrm{A}$, as a percentage of the injected activity, was calculated but no significant differences were found between the union and non-union groups at either the early or late uptakes at any of the three visits. No significant differences between the groups were found when the rate of uptake immediately after injection was calculated from the initial series of dynamic images.

The predictive value of the two-week, early uptake $\mathrm{A} / \mathrm{C}$ ratio was investigated. The intra-observer variation in the analysis of these results was found to be a mean of $6 \%$ between the measured uptake at the fracture site on two occasions six months apart. More important, however, is the inter-observer variation, as the investigator's choice of the region $\mathrm{C}$ will have important implications. The sensitivity and specificity of the early uptake $\mathrm{A} / \mathrm{C}$ ratio at two weeks was calculated independently by two of the authors using different $\mathrm{A} / \mathrm{C}$ cut-off values and the results are given in Table IV. As expected, there are differences in the ratios and these are reflected in the variation in the sensitivity and specificity. It appears that a cut-off value of 1.3 for the ratios provides an acceptable compromise between sensitivity and specificity. Sensitivity varied from $63 \%$ to $84 \%$ and the specificity was from $91 \%$ to $88 \%$ for the two operators. Neither the use of longitudinal profiles or of computer programs to define the region of interest provided any improvement over a skilled operator, and, in fact, the results were significantly worse.

The timing of the early scan at the first visit is important in relation to the time of injection but less so with regard to the time since fracture. In eight patients, uptake was measured from a 15-minute dynamic series of images; this showed a steady increase in the activity at the fracture site, and there was little variation from patient to patient (Fig. 4). This finding suggests that the $\mathrm{A} / \mathrm{C}$ ratios illustrated in Figure 2 are likely to differ significantly if the measurements are performed at a different time after injection of the isotope.

The variation of early uptake $\mathrm{A} / \mathrm{C}$ ratio with time since fracture in patients having normal union is illustrated in Figure 5. During the period from one week to four weeks after fracture there was no correlation between the $\mathrm{A} / \mathrm{C}$ ratio and the time since fracture. Four patients had scans even earlier, between one and seven days after fracture, though these results were not included in the main analysis. Two of these patients had

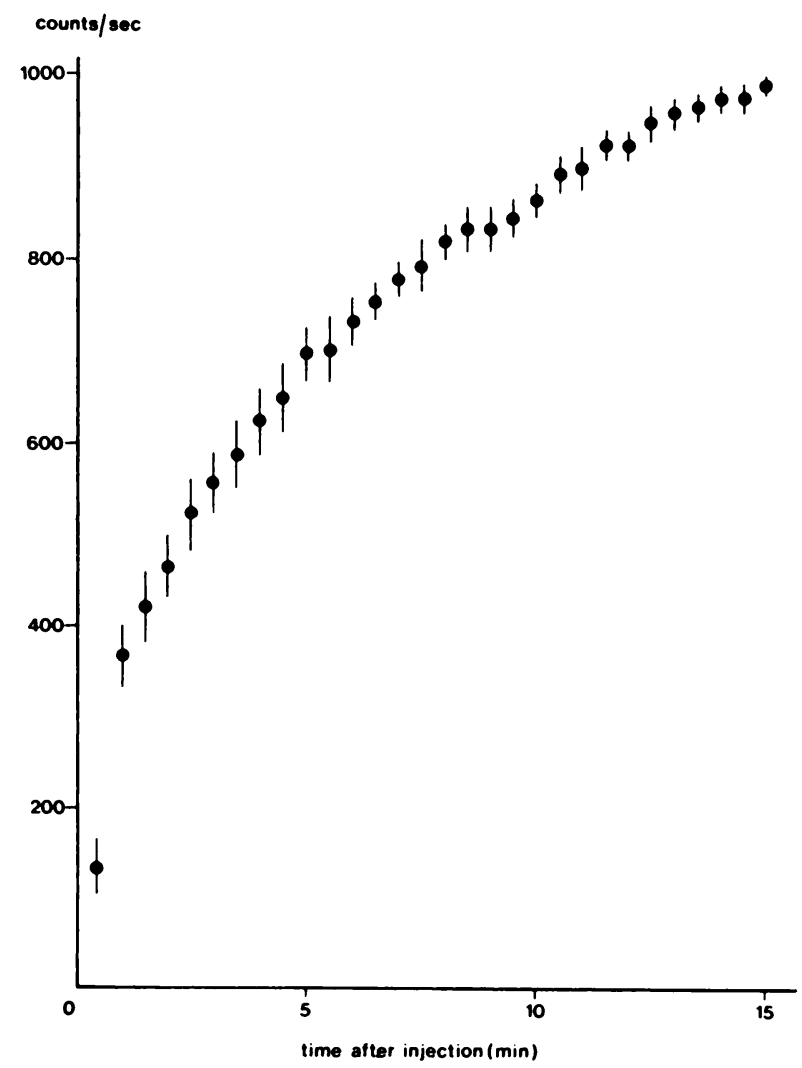

Fig. 4

Uptake at the fracture site during the first 15 minutes after injection, plotted as the mean \pm 2 standard errors from a series of eight patients. 


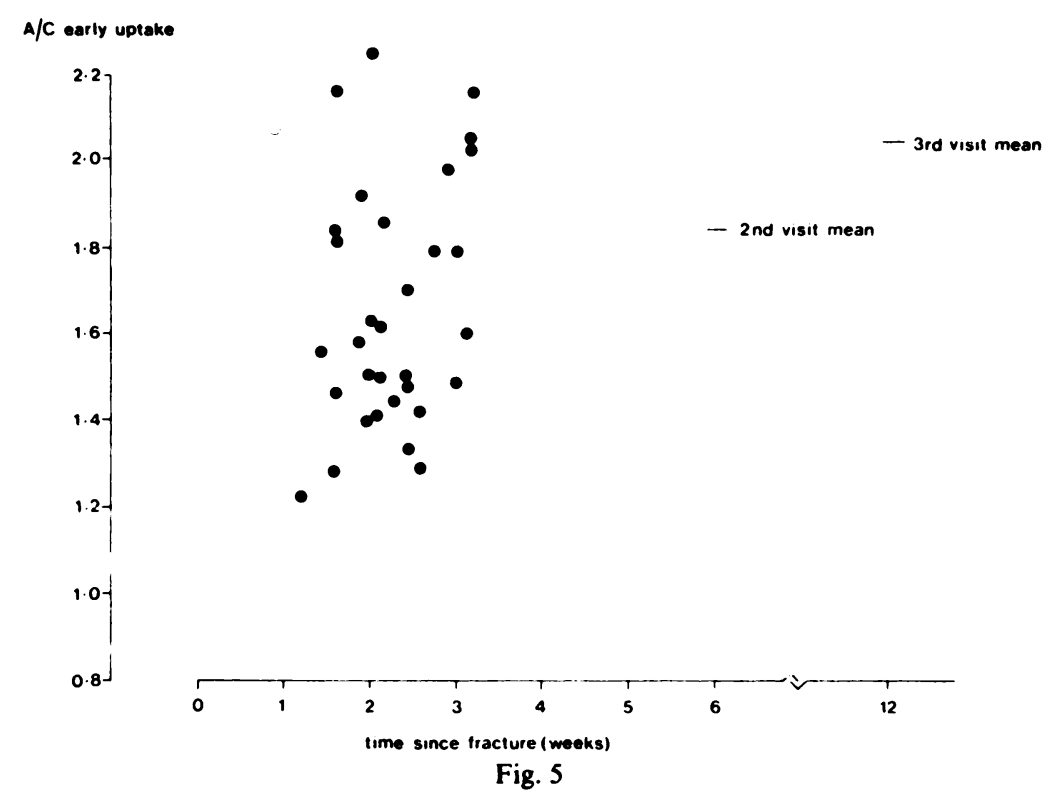

Results for the early uptake $\mathrm{A} / \mathrm{C}$ ratio at the first visit related to time since fracture. The open circles represent patients who were imaged less than one week after injury and were not included in the detailed analysis.

a very low ratio whereas those scanned after six days had results similar to those of the other patients. We concluded that the timing of the first scan after fracture is not particularly crucial to the ratio. Inspection of the bone scan images showed no appearance which was indicative of union or non-union, and in particular, no evident cold spots were seen in the scans of patients who proceeded to non-union.

\section{DISCUSSION}

Our results suggest that a quantitative MDP bone scan can help to predict non-union, but that the contralateral normal bone, as used by previous workers, does not provide a useful control site. Enough separation between the groups to enable a prediction to be made in an individual patient can only be achieved by using a normal region in the same limb as control.

One hypothesis is that, since disruption of the bone blood flow may be related to non-union, the early uptake result, which is predominantly related to blood flow, will be a better predictor than the late uptake, which is related to both blood flow and bone formation. This hypothesis can be extended, since it also explains why the greatest separation between the increased bone blood flow in bones which will unite, and its reduction in bones which will fail to unite, will be obtained at around the time of the maximum increase of blood flow. This period is likely to be nearer two weeks after injury than six or 12 weeks, and this explains our findings.

After a fracture blood flow increases to the whole of the bone, not just to the fracture site. This is why the use of a control region in the fractured limb rather than, as commonly chosen, a region in the contralateral normal leg, can compensate for variations between patients of the overall increase in blood flow. Thus the $\mathrm{A} / \mathrm{C}$ ratio will reflect variations in uptake at the fracture site alone. This may explain the smaller spread of the $\mathrm{A} / \mathrm{C}$ ratios in the group obtaining union (coefficient of variation $23 \%$ ) as compared with the $\mathrm{A} / \mathrm{B}$ ratios of $42 \%$.

Our results are in broad agreement with those of other workers. The mean values of the $A / B \div C / D$ and $\mathrm{C} / \mathrm{D}$ ratios agree well with those reported by Auchincloss and Watt (1982), and the inverse relationship they found between the late uptake C/D ratio at six weeks and the time to union is also confirmed. Auchincloss and Watt (1982) state that this finding is "difficult to rationalise and no data are available to explain this observation". A possible explanation is that the fracture produces a general increase in blood flow and activity at $C$ is increased relative to $D$. As the fracture heals, blood flow decreases and uptake at $C$ decreases; failure to unite may result in the continued higher activity at $\mathrm{C}$, resulting in the increased $C / D$ ratio for those with non-union. This theory is substantiated by our results; the C/D ratio is similar in the union group at two weeks to that in the non-union group at six weeks.

Jacobs et al. (1981) also used a control region in the fractured limb and investigated early uptake, but our uptake curves over the first 15 minutes (Fig. 4) are significantly different from the example given in their paper. We do not agree that the uptake between $7 \mathrm{~min}$ and $15 \mathrm{~min}$ is a "linear phase" which is "more an index of the affinity of the bone for phosphate and thus correlated with bone formation". Our images of the late uptake from one day to three weeks after fracture confirm the findings of Gregg et al. (1983) that "neither the presence of a cold spot nor any other scintigraphic feature could be correlated with the progress or time to fracture union". It must be noted, however, that we were using a high sensitivity collimator with consequent low resolution. 
The early uptake $A / C$ ratio at the first visit demonstrates a separation between patients proceeding to union and those who develop non-union, and there are acceptable levels of sensitivity and specificity at a cut-off level of 1.3, even when different operators are analysing the results. However, the same data has been used both to develop and to assess the accuracy of the various cutoff values, so the values for sensitivity and specificity may be over-optimistic. There is therefore a need to test the technique in a further prospective study.

There are important practical implications for the timing of measurements. The fact that the best results were achieved as early as two weeks after fracture would allow changes to be made in the management of the patient far earlier than by other methods and these changes could reduce the mean time to union. The routine application of the technique is relatively easy because the "early uptake" can be investigated in only 10 minutes of the patient's time. The proportion of our patients recorded as suffering non-union was higher, at $20 \%$, than the $13.5 \%$ quoted in a larger study by Ramadier et al. (1981). The reason is probably that we defined non-union as failure at six months; this is an important interval for clinical decision on further management. Auchincloss and Watt (1982) used the terms delayed union or unsatisfactory union for these patients and also had a lower incidence $(11.5 \%)$ than in our study. This difference may be due to the higher proportion of severely injured limbs in our study: we had $16 \%$ and $66 \%$ respectively in Groups III and II (Ellis 1958) compared with $9 \%$ and $33 \%$ in Auchincloss and Watts' series.

We would like to thank Mr J. Chalmers, Mr J. Christie, Mr M. J. McMaster, Mr M. F. Macnicol and W. M. McQuillan for their support. We would also like to thank Sister Bryson, Mrs J. Gormley and Mr J. Davies for their valuable assistance, and Mrs C. N. Rowan for secretarial services. This study was funded by the Scottish Home and Health Department.

\section{REFERENCES}

Auchincloss JM, Watt I. Scintigraphy in the evaluation of potential fracture healing: a clinical study of tibial fractures. $\mathrm{Br} J$ Radiol 1982;55:707-13.

Bauer GCH, Wendeberg B. External counting of $\mathrm{Ca}^{47}$ and $\mathrm{Sr}^{85}$ in studies of localised skeletal lesions in man. J Bone Joint Surg [Br] $1959 ; 41-B: 558-80$
Desai A, Alavi A, Dalinka M, Brighton C, Esterhai J. Role of bone scintigraphy in the evaluation and treatment of nonunited fractures: concise communication. J Nucl Med 1980;2(10):913-4.

Ellis $H$. The speed of healing after fracture of the tibial shaft. $J$ Bone Joint Surg [Br] 1958; 40-B:42-6.

Gregg PJ, Barsoum MK, Clayton CB. Scintigraphic appearance of the tibia in the early stages following fracture. Clin Orthop 1983;175:139-46.

Gustilo RB, Anderson JT. Prevention of infection in the treatment of one thousand and twenty-five open fractures of long bones: retrospective and prospective analysis. J Bone Joint Surg [Am] 1976;58-A:453-8.

Hughes S. Radionuclides in orthopaedic surgery. J Bone Joint Surg [Br] 1980;62-B:141-50.

Hughes S, Khan R, Davies R, Lavender P. The uptake by the canine tibia of the bone scanning agent ${ }^{99} \mathrm{~m} \mathrm{Tc}-\mathrm{MDP}$ before and after an osteotomy. J Bone Joint Surg [Br] 1978;60-B:579-82.

Hughes SPF, Pinto MR, Fleming RH, McCarthy ID. The volume of distribution of albumin and methylene diphosphonate in normal and infected bone. J Bone Joint Surg [Br] 1986;68-B:841.

Illingworth GI, Schiess FA. Strontium $87 \mathrm{~m}$ in the prognosis of fractures of the tibia. Proc R Soc Med $1971 ; 64: 633-4$.

Jacobs RR, Jackson RP, Preston DF, Williamson JA, Gallagher J. Dynamic bone scanning in fractures. Injury 1981;12:455-9.

Johanssen A. Fracture healing controlled by ${ }^{87 \mathrm{~m}} \mathrm{Sr}$ uptake. Acta Orthop Scand 1973;44:628-39.

Johner R, Wruhs $\mathbf{O}$. Classification of tibial shaft fractures and correlation with results after rigid internal fixation. Clin Orthop 1983;178:7-25

Lavender JP, Khan RAA, Hughes SPF. Blood flow and tracer uptake in normal and abnormal canine bone. J Nucl Med 1979;20:413-8.

Lund B, Lund JO, Sorensen OH, Lund B. Evaluation of fracture healing in man by serial ${ }^{99 m} \mathrm{Tc}$-Sn-pyrophosphate scintimetry. Acta Orthop Scand 1978;49:435-9.

McCarthy ID, Hughes SPF. Extraction of ${ }^{99 \mathrm{~m} T c-m e t h y l e n e ~ d i p h o s-~}$ phonate as a function of bone blood flow. In: Arlet J, Ficat RP, Hungerford DS, eds. Bone circulation. Baltimore, etc: Williams \& Williams, 1984:167-70.

Makler PT Jr, Charkes ND. Studies of skeletal tracer kinetics. IV Optimum delay time for $\mathrm{Tc}-99 \mathrm{~m}(\mathrm{Sn})$ methylene diphosphonate bone imaging. J Nucl Med 1980;21:641-5.

Matin P. The appearance of bone scans following fractures, including immediate and long term studies. J Nucl Med 1979;20:1227-31.

Muheim G. Assessment of fracture healing in man by serial $87 \mathrm{~m}$ Strontium-scintimetry. Acta Orthop Scand 1973;44:621-7.

Paradis GR, Kelly PJ. Blood flow and mineral deposition in canine tibial fractures. J Bone Joint Surg [Am] 1975;57-A :220-6.

Ramadier JO, Lecestre P, Camilleri A, Bomhart M, Mazas F, Witvoet J, Zucman P. Fractures ouvertes de jambe: étude de 818 cas. Int Orthop $1981 ; 5: 169-82$.

Riggens RS, DeNardo GL, D'Ambrosia R, Goldman M. Assessment of circulation in the femoral head by $18 \mathrm{~F}$ scintigraphy. $J$ Nucl Med 1974;15:183-6.

Tucker FR. The use of radioactive phosphorus in the diagnosis of avascular necrosis of the femoral head. $J$ Bone Joint Surg [Br] 1950;32-B:100-7. 